\title{
Reactive transport modeling of acid gas generation and condensation
}

\author{
GUOXIANg ZHANG, NiCOLAS SPYCHER, ERIC \\ SONNENTHAL AND CARL STEEFEL
}

Lawrence Berkeley National Laboratory, Berkeley, CA (gxzhang@lbl.gov)

Pulvirenti et al. (2004) recently conducted a laboratory evaporation/condensation experiment on a synthetic solution of primarily calcium chloride. This solution represents one potential type of evaporated pore water at Yucca Mountain, Nevada, a site proposed for geologic storage of high-level nuclear waste. These authors reported that boiling this solution to near dryness (a concentration factor $>75,000$ relative to actual pore waters) leads to the generation of acid condensate $(\mathrm{pH}<1.5)$ presumably due to volatilization of $\mathrm{HCl}$ (and minor $\mathrm{HF}$ and/or $\mathrm{HNO}_{3}$ ). To investigate the various processes taking place, including boiling, gas transport, and condensation, their experiment was simulated by modifying an existing multicomponent and multiphase reactive transport code (TOUGHREACT). This code was extended with a Pitzer ion-interaction model to deal with high ionic strength. The model of the experiment was set-up to capture the observed increase in boiling temperature $\left(143^{\circ} \mathrm{C}\right.$ at $\sim 1$ bar) resulting from high concentrations of dissolved salts (up to 8 $\left.\mathrm{m} \mathrm{CaCl}_{2}\right)$. The computed $\mathrm{HCl}$ fugacity $\left(\sim 10^{-4}\right.$ bars) generated by boiling under these conditions is not sufficient to lower the $\mathrm{pH}$ of the condensate (cooled to 80 and $25^{\circ} \mathrm{C}$ ) down to observed values unless the $\mathrm{H}_{2} \mathrm{O}$ mass fraction in gas is reduced below $\sim 10 \%$. This is because the condensate becomes progressively diluted by $\mathrm{H}_{2} \mathrm{O}$ gas condensation. However, when the system is modeled to remove water vapor, the computed $\mathrm{pH}$ of instantaneous condensates decreases to $\sim 1.7$, consistent with the experiment (Figure 1). The results also show that the $\mathrm{HCl}$ fugacity increases, and calcite, gypsum, sylvite, halite, $\mathrm{MgCl}_{2} 4 \mathrm{H}_{2} \mathrm{O}$ and $\mathrm{CaCl}_{2}$ precipitate sequentially with increasing concentration factors.

Figure 1. $\mathrm{pH}$ of the condensate

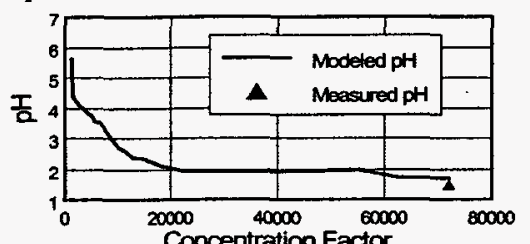

References:

Pulvirenti, A.L., K.M. Needham, M.A. Adel-Hadadi, A. Barkatt, C.R. Marks, and J.A. Gorman, (2004), Corrosion 2004, NACE International, New Orleans. 